\title{
Microwave Assisted Sol-Gel Synthesis of MgO Nanoparticles and Their Catalytic Activity in the Synthesis of Hantzsch 1,4-Dihydropyridines
}

\author{
Hakimeh MIRZAEI, Abolghasem DAVOODNIA* \\ Department of Chemistry, Mashhad Branch, Islamic Azad University, Mashhad, Iran
}

\begin{abstract}
A microwave-assisted sol-gel method was employed for the preparetion of nano-sized MgO particles using $\mathrm{Mg}\left(\mathrm{NO}_{3}\right)_{2} \cdot 6 \mathrm{H}_{2} \mathrm{O}$ as precursor and deionized water as solvent. The sample calcined at $500{ }^{\circ} \mathrm{C}$ had a high specific surface area of $243.2 \mathrm{~m}^{2} / \mathrm{g}$ and particles sizes from 9.5 to $10.5 \mathrm{~nm}$. For comparison, MgO nanoparticles were also synthesized without microwave irradiation. X-ray diffraction (XRD) characterization showed the formation of smaller particles after microwave irradiation. The structure and morphology of the MgO particles were analyzed by $\mathrm{N}_{2}$ adsorption-desorption, XRD, scanning electron microscopy, and transmission electron microscopy. Their catalytic behavior was studied with the one-pot synthesis of Hantzsch 1,4-dihydropyridines from the reaction of aromatic aldehydes, ethyl acetoacetate, and ammonium acetate. The MgO nanoparticles have high catalytic activity and gave the desired products in good to high yields. The catalyst can be easily recovered by filtration and was used at least three times with only a slight reduction in its catalytic activity.
\end{abstract}

Key words: magnesium oxide; microwave-assisted sol-gel method; nanoparticle; Hantzsch 1,4-dihydropyridine

CLC number: O643 Document code: A

Received 12 April 2012. Accepted 6 June 2012.

*Corresponding author.Tel: +98-511-8435000; Fax:+98-511-8424020; E-mail: adavoodnia@mshdiau.ac.ir,adavoodnia@yahoo.com

This work was supported by Islamic Azad University, Mashhad Branch.

English edition available online at Elsevier ScienceDirect (http://www.sciencedirect.com/science/journal/18722067).

Magnesium oxide has wide applications in the detection and remediation of chemical waste and warfare agents [1], is additive in heavy fuel oils [2] and reflecting and antireflecting coatings [3], and is used in superconducting and ferroelectric thin films as the substrate [4-6]. In the field of catalysis, magnesium oxide has promising applications as both catalyst and catalyst support in many organic reactions [7-11].

Recently, nanoparticles as catalysts [12-15] have attracted much attention. As the particle size decreases, the relative number of surface atoms increases, and thus the activity increases. The high surface area material is of interest as catalyst and catalyst support. The sol-gel technique is advantageous in the synthesis of nano-sized materials because it has the advantages of simple procedure, low crystallization temperature, and low cost [16-21]. Factors such as temperature, time, $\mathrm{pH}$, catalytic agent for gel formation, and the environmental conditions affect the final product [22-24]. There are several methods for the synthesis of nano-sized MgO particles including the sol-gel method [25], chemical gas phase deposition [26], laser vaporization [27], hydrothermal synthesis [28], and combustion aerosol synthesis [29]. The morphology and properties of the resulting $\mathrm{MgO}$ differ and depend on the synthesis route and processing conditions.

Microwave-assisted synthesis has attracted much atten- tion because it has advantages of being faster, simpler, and more energy efficient [30,31]. In the microwave-assisted sol-gel method, the precursor solution is irradiated by a microwave source. The efficient energy transfer can result in a rapid heating process. Furthermore, microwave heating can result in the homogeneous heating of the precursor solution in a rather short time to achieve a uniform distribution of particle size. Consequently, the microwave hydrothermal process is more efficient than the conventional hydrothermal process for preparing various oxide nanoparticles [32,33]. In this paper, we report a new facile route for the synthesis of nanocrystalline MgO with high surface area using a microwave-assisted sol-gel method. Our interest is in the application of reusable catalysts in organic reactions [34-38], and the catalytic performance of the synthesized $\mathrm{MgO}$ nanoparticles in the synthesis of 1,4-dihydropyridines by the reaction of aromatic aldehydes, ethyl acetoacetate, and ammonium acetate was also investigated (Scheme 1).

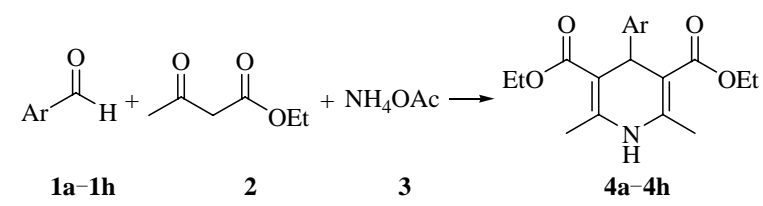

Scheme 1. Synthesis of Hantzsch 1,4-dihydropyridines catalyzed by MgO nanoparticles. 


\section{Experimental}

\subsection{Synthesis of MgO nanoparticles}

The MgO nanoparticles were synthesized by the precipitation of magnesium hydroxide gels in aqueous solution using $\mathrm{Mg}\left(\mathrm{NO}_{3}\right)_{2} \cdot 6 \mathrm{H}_{2} \mathrm{O}$ as salt and ammonia solution as the precipitating agent. First, $0.1 \mathrm{~mol} / \mathrm{L}$ magnesium nitrate solution was prepared by dissolving $\mathrm{Mg}\left(\mathrm{NO}_{3}\right)_{2} \cdot 6 \mathrm{H}_{2} \mathrm{O}$ (Merck) in deionized water. The $\mathrm{pH}$ of $200 \mathrm{ml}$ deionized water was adjusted to 10.5 by the addition of ammonia solution (25\%), and to this solution, $0.1 \mathrm{~mol} / \mathrm{L}$ magnesium nitrate solution was added dropwise with vigorous stirring. During the addition, the $\mathrm{pH}$ of the mixture decreased due to the hydrolysis of the salt. The $\mathrm{pH}$ was maintained at 10.5 by the controlled addition of ammonia solution. After completion of the precipitation procedure, the $\mathrm{Mg}(\mathrm{OH})_{2}$ gel was transferred into the Milestone microwave oven (MicroSYNTH) operated at $350 \mathrm{~W}$ for $15 \mathrm{~min}$. During the microwave irradiation, the temperature of the solution reached $80{ }^{\circ} \mathrm{C}$. The resulting precipitate was then cooled to room temprature, filtered, and washed with deionized water more than five times. The solid obtained was dried at $120{ }^{\circ} \mathrm{C}$ for $1 \mathrm{~h}$ and calcined at $500{ }^{\circ} \mathrm{C}$ for $2 \mathrm{~h}$ to give the final product.

\subsection{Characterization of MgO nanoparticles}

Thermal gravimetric and differential thermal gravimetry (TGA/DTG) analyses were performed using air as the oxidant at the heating rate of $5^{\circ} \mathrm{C} / \mathrm{min}$ on a Shimadzu TGA-50 system. The BET surface area of the material was measured by $\mathrm{N}_{2}$ adsorption-desorption with a Quantachrome instrument Model Autosorb1, USA. X-ray diffraction (XRD) was performed with a Bruker D8-Advance X-ray diffractometer using graphite monochromatized high intensity $\mathrm{Cu} K_{\alpha}$ radiation $(\lambda=0.15406 \mathrm{~nm})$. Scanning electron microscopy (SEM) images were obtained by a Hitachi S 4160, Japan. Transmission electron microscopy (TEM) was performed with CM Philips operated at $120 \mathrm{kV}$.

\subsection{General procedure for the synthesis of 1,4-dihydropyridines}

A mixture of an aromatic aldehyde $\mathbf{1 a}-\mathbf{1 h}$ (1 mmol), ethyl acetoacetate 2 (2 mmol), ammonium acetate 3 (1 mmol), and MgO nanoparticles (0.04 g) as a catalyst in ethanol (5 $\mathrm{ml}$ ) was heated under reflux for the appropriate time. The progress of the reaction was monitored by TLC. Upon completion, the catalyst was filtered while hot. Ethanol was evaporated under vacuum and cold water was then added. The product was extracted with chloroform, the chloroform layer was heated at $50{ }^{\circ} \mathrm{C}$ under vacuum to dryness, and the residue was collected and washed with n-hexane to give 1,4-dihydropyridines $\mathbf{4 a - 4 h}$ in good to high yields.

Melting points were recorded on a Stuart SMP3 melting point apparatus. The IR spectra were obtained using $\mathrm{KBr}$ disks on a Bruker Tensor 27 spectrophotometer. The ${ }^{1} \mathrm{H}$ NMR (400 \& $500 \mathrm{MHz}$ ) spectra were recorded with a Bruker 400 \& 500 spectrometer.

\subsection{Recycling and reusing of the catalyst}

Due to the fact that the catalyst was insoluble in hot ethanol, it can be recycled by simple filtration. The separated catalyst was washed with cold ethanol, dried at $80{ }^{\circ} \mathrm{C}$ under vacuum for $2 \mathrm{~h}$, and reused in the reaction.

\section{Results and discussion}

\subsection{Characterization results of the MgO nanoparticles}

TGA/DTG analysis of the oven-dried magnesium hydroxide were investigated by raising its temperature at the rate of $5{ }^{\circ} \mathrm{C} / \mathrm{min}$ in air up to $800^{\circ} \mathrm{C}$ to analyze its thermal decomposition behavior. Figure 1 shows the TGA/DTG curves of the as-prepared magnesium hydroxide. Only one main stage of mass loss was observed. The strong peak observed at $359.59{ }^{\circ} \mathrm{C}$ in the derivative thermogram can be attributed to the decomposition of $\mathrm{Mg}(\mathrm{OH})_{2}$ to $\mathrm{MgO}$. The observed mass loss at $360{ }^{\circ} \mathrm{C}$ was $31.3 \%$, which was in good agreement with the nominal value for the $\mathrm{Mg}(\mathrm{OH})_{2}$ to MgO transformation (30.8\%).

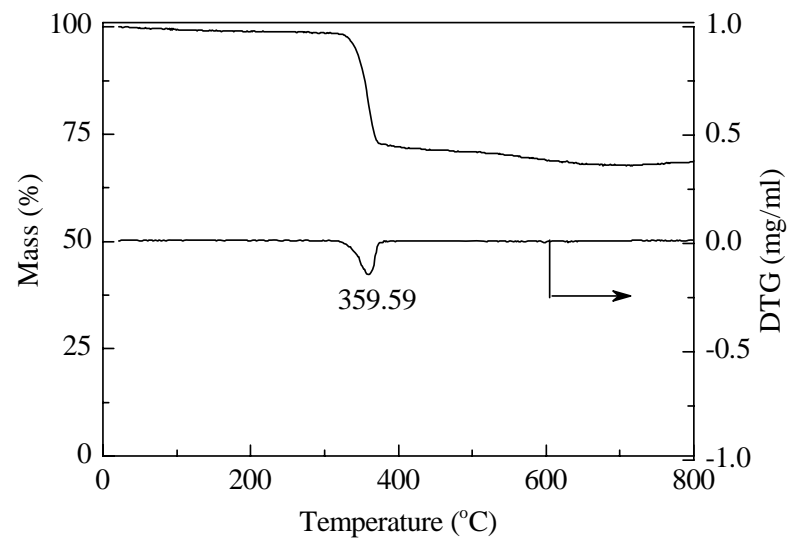

Fig. 1. TGA/DTG curves of the $\mathrm{Mg}(\mathrm{OH})_{2}$.

The specific surface area of the calcined sample at $500^{\circ} \mathrm{C}$ measured by different methods was in the range of 243.2 to $272.4 \mathrm{~m}^{2} / \mathrm{g}$ (Table 1). As shown in Table 1, the sample has a high specific surface area, high specific total volume, and small pore diameter. The $\mathrm{N}_{2}$ adsorption-desorption isotherm of the sample is shown in Fig. 2. The BET analysis was also performed for the sample calcined at $650{ }^{\circ} \mathrm{C}$. The specific 
Table $1 \quad \mathrm{~N}_{2}$ adsorption-desorption results for the MgO nanoparticles

\begin{tabular}{|c|c|c|c|c|c|c|}
\hline \multicolumn{3}{|c|}{$\begin{array}{c}\text { Specific surface area } \\
\left(\mathrm{m}^{2} / \mathrm{g}\right)\end{array}$} & \multicolumn{2}{|c|}{$\begin{array}{c}\text { Pore diameter } \\
(\mathrm{nm})\end{array}$} & \multicolumn{2}{|c|}{$\begin{array}{c}\text { Pore volume } \\
(\mathrm{ml} / \mathrm{g})\end{array}$} \\
\hline BET & $\mathrm{BJH}$ & DH & BJH & DH & BJH & DH \\
\hline 243.2 & 264.0 & 272.4 & 2.9 & 2.9 & 0.308 & 0.307 \\
\hline
\end{tabular}

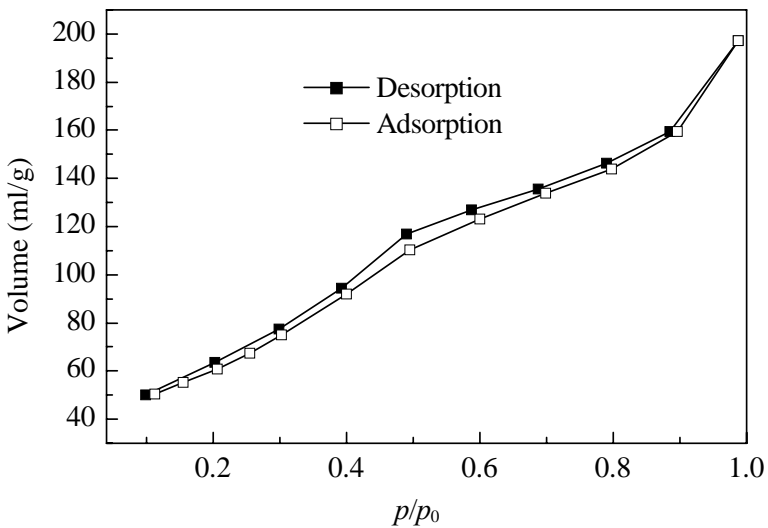

Fig. 2. $\mathrm{N}_{2}$ adsorption-desorption isotherm of the $\mathrm{MgO}$ nanoparticles prepared with irradiation by microwave and calcined at $500{ }^{\circ} \mathrm{C}$.

surface area of the MgO nanoparticles decreased from 243.2 to $131 \mathrm{~m}^{2} / \mathrm{g}$ with increasing temperature from 500 to 650 ${ }^{\circ} \mathrm{C}$.

The XRD pattern of the MgO sample calcined at $500{ }^{\circ} \mathrm{C}$ is presented in Fig. 3(1). All the peaks in Fig. 3(1) could be indexed to cubic MgO crystallites with the lattice parameter $a=0.421 \mathrm{~nm}$ using the standard values of JCPDS 45-946. No peak arising from an impurity was observed in Fig. 3(1).

The average particle size in the calcined MgO nanoparticles was estimated by the Debye-Scherrer equation [39]: $D$ $=k \lambda / \beta \cos \theta$, where $D$ is the crystal size, $k$ is the shape factor, which usually takes a value of about 0.9 [40], $\lambda$ is the wavelength of $\mathrm{X}$-ray source used, $\beta$ is the full width at half-maximum (FWHM), and $\theta$ is the Bragg diffraction angle. The average particle size of $\mathrm{MgO}$ calcined at $500{ }^{\circ} \mathrm{C}$

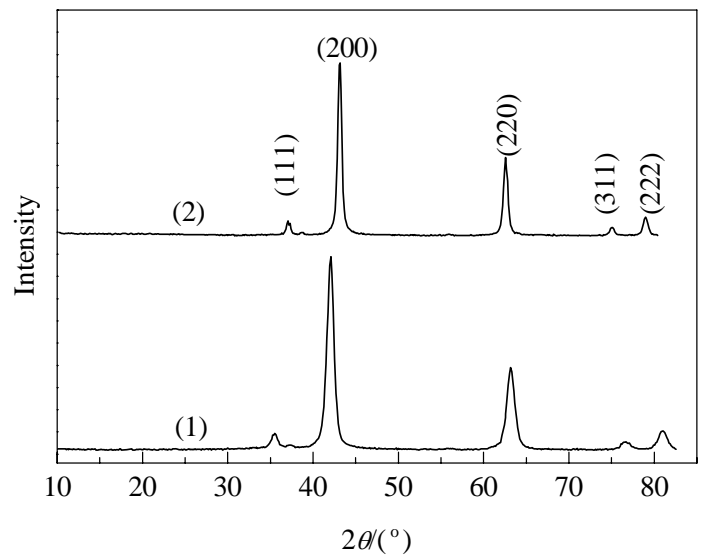

Fig. 3. XRD patterns of the $\mathrm{MgO}$ nanoparticles calcined at $500{ }^{\circ} \mathrm{C}$ with (1) and without (2) irradiation by microwave. was estimated to be $10.0 \mathrm{~nm}$ (Fig. 3(1)).

For comparison and to show the effect of microwave irradiation, MgO nanoparticles were also synthesized without irradiation by microwave. After completion of the precipitation procedure, the $\mathrm{Mg}(\mathrm{OH})_{2}$ gel was dried at $120^{\circ} \mathrm{C}$ for $1 \mathrm{~h}$ and calcined at $500{ }^{\circ} \mathrm{C}$ for $2 \mathrm{~h}$. The average particle size of $\mathrm{MgO}$ synthesized under these conditions was $16.7 \mathrm{~nm}$ (Fig. $3(2)$ ). The broadening of the FWHM in the XRD spectrum indicated the formation of smaller particles after microwave irradiation.

The SEM and TEM images of the MgO nanoparticles are shown in Fig. 4. The particle size of the MgO sample was typically in the range of 30 to $50 \mathrm{~nm}$.

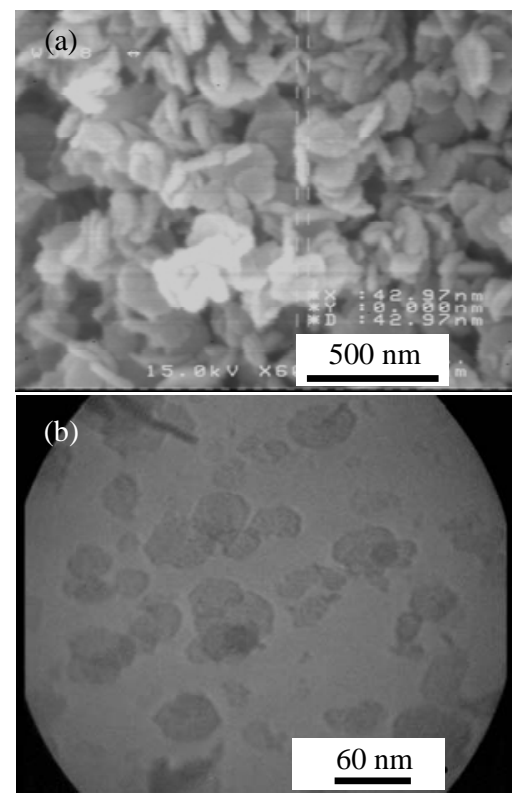

Fig. 4. SEM (a) and TEM (b) images of MgO nanoparticles synthesized with irradiation by microwave and calcined at $500^{\circ} \mathrm{C}$.

\subsection{Catalytic activity of the MgO nanoparticles in the synthesis of 1,4-dihydropyridines}

In order to evaluate the catalytic efficiency of the $\mathrm{MgO}$ nanoparticles in the synthesis of 1,4-dihydropyridines and to determine the most appropriate reaction conditions, initially a model study was carried out on the synthesis of compound 4c by the cyclocondensation of 4-chlorobenzaldehyde (1 mmol), ethyl acetoacetate ( $2 \mathrm{mmol})$, and ammonium acetate (1 mmol) under different sets of reaction conditions (Table 2). With the various solvents of EtOH, $\mathrm{CHCl}_{3}, \mathrm{H}_{2} \mathrm{O}$, $\mathrm{CH}_{3} \mathrm{CN}, \mathrm{CH}_{2} \mathrm{Cl}_{2}$, and also under solvent-free conditions, and with various amounts of the catalyst, the reaction was faster and proceeded to give the highest yield with $0.04 \mathrm{~g}$ of $\mathrm{MgO}$ nanoparticles in EtOH at reflux temperature (entry 5). More catalyst decreased the yield of the product (entries 6 and 7). It also should be noted that recently Antonyraj et al. [41] have reported that in the synthesis of 1,4-dihydropyri- 
Table 2 Synthesis of compound $\mathbf{4 c}$ in the presence of MgO nanoparticles as catalyst under different reaction conditions

\begin{tabular}{|c|c|c|c|c|c|}
\hline & & 2 & 3 & & $\mathrm{O}$ \\
\hline Entry & $\begin{array}{c}\text { Catalyst } \\
\text { (g) }\end{array}$ & Solvent & $T /{ }^{\circ} \mathrm{C}$ & $\begin{array}{l}\text { Time } \\
\text { (min) }\end{array}$ & $\begin{array}{c}\text { Yield }^{*} \\
(\%)\end{array}$ \\
\hline 1 & - & $\mathrm{EtOH}$ & reflux & 120 & trace \\
\hline 2 & 0.02 & $\mathrm{EtOH}$ & reflux & 200 & 75 \\
\hline 3 & 0.04 & $\mathrm{EtOH}$ & r.t. & 190 & 70 \\
\hline 4 & 0.04 & $\mathrm{EtOH}$ & 50 & 170 & 82 \\
\hline 5 & 0.04 & $\mathrm{EtOH}$ & reflux & 165 & 90 \\
\hline 6 & 0.06 & $\mathrm{EtOH}$ & reflux & 165 & 80 \\
\hline 7 & 0.10 & $\mathrm{EtOH}$ & reflux & 165 & 78 \\
\hline 8 & 0.04 & $\mathrm{CHCl}_{3}$ & reflux & 225 & 65 \\
\hline 9 & 0.04 & $\mathrm{H}_{2} \mathrm{O}$ & reflux & 180 & 80 \\
\hline 10 & 0.04 & $\mathrm{CH}_{3} \mathrm{CN}$ & reflux & 260 & 42 \\
\hline 11 & 0.04 & $\mathrm{CH}_{2} \mathrm{Cl}_{2}$ & reflux & 240 & 60 \\
\hline 12 & 0.15 & solvent-free & 100 & 180 & 42 \\
\hline
\end{tabular}

Other conditions: $1 \mathrm{mmol}$ 4-chlorobenzaldehyde, 2 mmol ethyl acetoacetate, $1 \mathrm{mmol}$ ammonium acetate.

"Isolated yield of the pure product based on 4-chlorobenzaldehyde.

dines, increasing the amount of $\mathrm{MgAl}_{2}-\mathrm{HT}$ as a solid base catalyst similarly decreased the yield of the product. Careful monitoring of the model reaction by TLC showed that in the presence of 0.06 and $0.10 \mathrm{~g}$ of the catalyst, small amounts of unidentified side-products appeared and therefore the yield of compound $\mathbf{4 c}$ decreased.

Encouraged by this success and in order to evaluate the generality of this model reaction, we extended the reaction to the use of other aromatic aldehydes with ethyl acetoacetate, and ammonium acetate under the optimized reaction conditions. As shown in Table 3, different aromatic aldehydes were reacted successfully and gave the expected products $\mathbf{4 a - 4 h}$ in good to high yields.

To show the merit of the MgO nanoparticles synthesized with irradiation by microwave (Cat. 1) as a heterogeneous catalyst, the results were compared with those using other heterogeneous catalysts reported for the synthesis of 1,4-dihydropyridines [41,42,44-46]. This comparison is shown in Table 4. As can be seen, Cat. 1 gave the expected products in good to high yields in relatively shorter reaction times.

The activities of nano $\mathrm{ZnO}$ [47] and the $\mathrm{MgO}$ nanoparticles synthesized without irradiation by microwave (Cat. 2) as the catalyst in the synthesis of compound $\mathbf{4} \mathbf{c}$ were also investigated. Although under the optimized reaction conditions, compound 4c was obtained in 90\% yield after 165
Table 3 Synthesis of Hantzsch 1,4-dihydropyridines 4a-4h using $\mathrm{MgO}$ nanoparticles as catalyst under the optimized conditions

\begin{tabular}{|c|c|c|c|c|c|c|}
\hline \multirow{2}{*}{ Entry } & \multirow{2}{*}{$\mathrm{Ar}$} & \multirow{2}{*}{$\begin{array}{l}\text { Pro- } \\
\text { ducts }^{\mathrm{a}}\end{array}$} & \multirow{2}{*}{$\begin{array}{l}\text { Time } \\
\text { (min) }\end{array}$} & \multirow{2}{*}{$\begin{array}{c}\text { Yield }^{\mathrm{b}} \\
(\%)\end{array}$} & \multicolumn{2}{|c|}{ Melting point $\left({ }^{\circ} \mathrm{C}\right)$} \\
\hline & & & & & Found & Reported \\
\hline 1 & & $4 a$ & 110 & 85 & $155-157$ & 156-158 [42] \\
\hline 2 & & $4 b$ & 130 & 88 & $162-163$ & 162-164 [42] \\
\hline 3 & & $4 c$ & 165 & 90 & $146-149$ & 144-146 [43] \\
\hline 4 & & $4 d$ & 110 & 83 & 230-233 & 230-232 [43] \\
\hline 5 & & $4 e$ & 95 & 90 & $160-161$ & 158-160 [42] \\
\hline 6 & & $4 f$ & 80 & 92 & 136-138 & 135-137 [43] \\
\hline 7 & & $4 \mathrm{~g}$ & 190 & 78 & $161-163$ & 163-165 [42] \\
\hline & & & & & & \\
\hline 8 & & $4 h$ & 200 & 73 & $131-134$ & 130-132 [42] \\
\hline
\end{tabular}

Reaction conditions: $1 \mathrm{mmol}$ aryl aldehyde, $2 \mathrm{mmol}$ ethyl acetoacetate, $1 \mathrm{mmol}$ ammonium acetate, $0.04 \mathrm{~g} \mathrm{MgO}$ nanoparticles in ethanol at reflux temperature.

${ }^{\mathrm{a}}$ All the products were characterized by ${ }^{1} \mathrm{H}$ NMR and IR spectral data and comparision of their melting points with those of authentic samples.

${ }^{\mathrm{b}}$ Isolated yield of the pure product based on aryl aldehyde.

min using Cat. 1 (Table 2, entry 5), using 0.04 g nano $\mathrm{ZnO}$ as the catalyst gave the same product only in $55 \%$ yield after $180 \mathrm{~min}$. Also, in the presence of $0.04 \mathrm{~g}$ Cat. 2 under the same reaction conditions, product $\mathbf{4 c}$ was obtained in $75 \%$ yield after 165 min (Table 4). Since in the $\mathrm{MgO}$ nanoparticles, the $\mathrm{O}$ is a relatively high strength Brönsted basic site [48], the higher activity of Cat. 1 than nano $\mathrm{ZnO}$ in this reaction was attributed to the higher basisity of $\mathrm{MgO}$ than $\mathrm{ZnO}$. On the other hand, this comparison also showed that there was a relationship between the size of nanoparticles and their activity. Cat. 1 with the size of $10.0 \mathrm{~nm}$ has a higher activity than Cat. 2 with the size of $16.7 \mathrm{~nm}$.

Table 4 Comparison of various solid catalysts in the synthesis of 1,4-dihydropyridines

\begin{tabular}{|c|c|c|c|c|c|}
\hline Catalyst & Solvent & $T /{ }^{\circ} \mathrm{C}$ & $\begin{array}{l}\text { Time } \\
(\mathrm{min})\end{array}$ & $\begin{array}{l}\text { Yield } \\
(\%)\end{array}$ & Ref. \\
\hline $\mathrm{MgAl}_{2}-\mathrm{HT}$ & $\mathrm{CH}_{3} \mathrm{CN}$ & r.t. & 390 & $32-75$ & [41] \\
\hline $\mathrm{PPh}_{3}$ & EtOH & reflux & $120-300$ & $72-95$ & [42] \\
\hline Cellulose sulfuric acid & - & 100 & $120-300$ & $78-92$ & [44] \\
\hline $\mathrm{NaHSO}_{4}-\mathrm{SiO}_{2}$ & $\mathrm{CH}_{3} \mathrm{CN}$ & r.t. & $300-480$ & $75-90$ & {$[45]$} \\
\hline $\begin{array}{l}\text { 3,4,5-trifluorobenzene } \\
\text { boronic acid }\end{array}$ & [bmim]Cl & r.t. & $240-360$ & $85-93$ & {$[46]$} \\
\hline Cat. 1 & $\mathrm{EtOH}$ & reflux & 80-200 & 73-92 & this work \\
\hline Nano $\mathrm{ZnO}^{*}$ & $\mathrm{EtOH}$ & reflux & 180 & 55 & this work \\
\hline Cat. $2^{*}$ & $\mathrm{EtOH}$ & reflux & 165 & 75 & this work \\
\hline
\end{tabular}

${ }^{*}$ Tested for the synthesis of compound $\mathbf{4 c}$. 
The reusability of the catalyst was also investigated. For this purpose, the same model reaction was again studied under the optimized conditions. After the completion of the reaction, the catalyst was recovered using the procedure described in the experimental section and reused for the reaction. The catalyst could be used at least three times with only a slight reduction in the catalytic activity (90\% yield for 1st use; $88 \%$ for 2nd use; $85 \%$ for 3rd use).
A reaction mechanism is proposed in Scheme 2. In $\mathrm{MgO}$ nanoparticles, there are acid-base bifunctional sites where $\mathrm{Mg}$ and $\mathrm{O}$ act as a weak Lewis acidic site and relatively high strength Brönsted basic site, respectively. These acid-base bifunctional sites facilitate the formation of intermediates $\mathbf{I}$ and $\mathbf{I I}$ that then react to give the final products 4a-4h. Under these conditions, attempts to isolate the intermediates I and II failed.
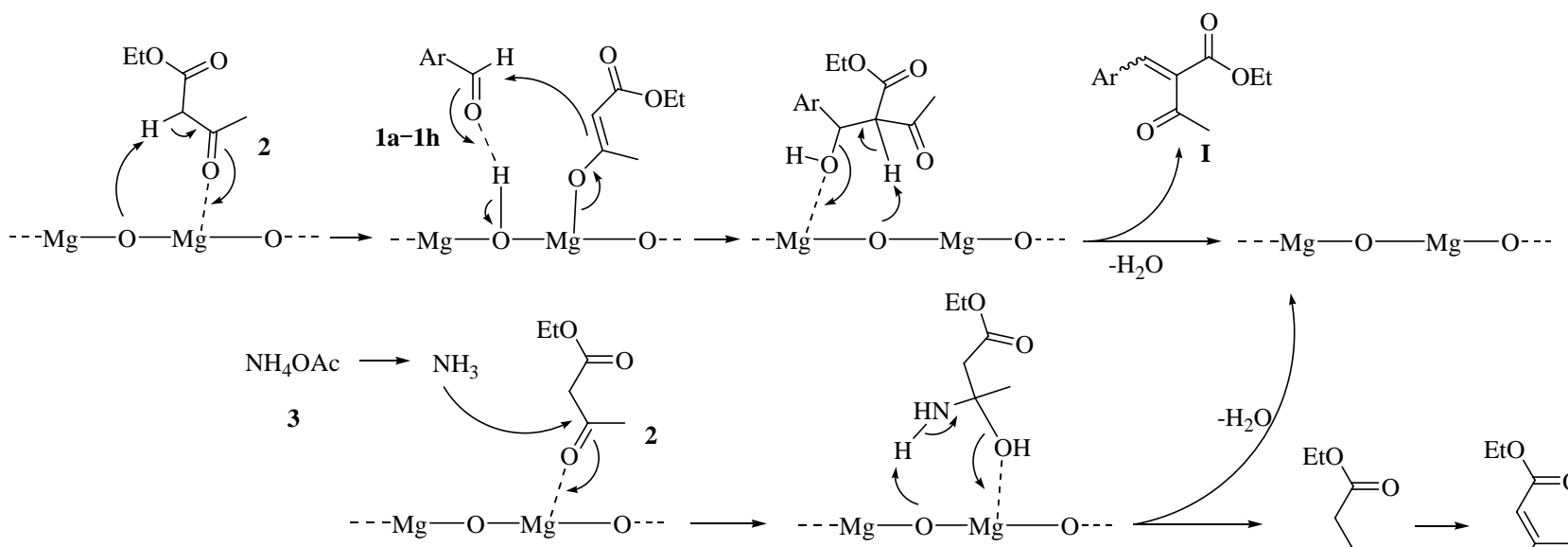

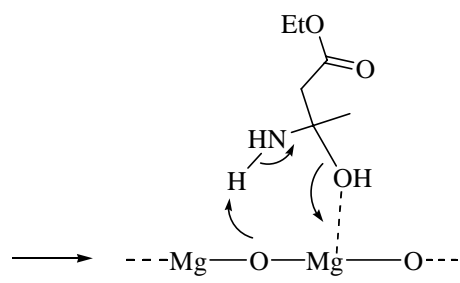
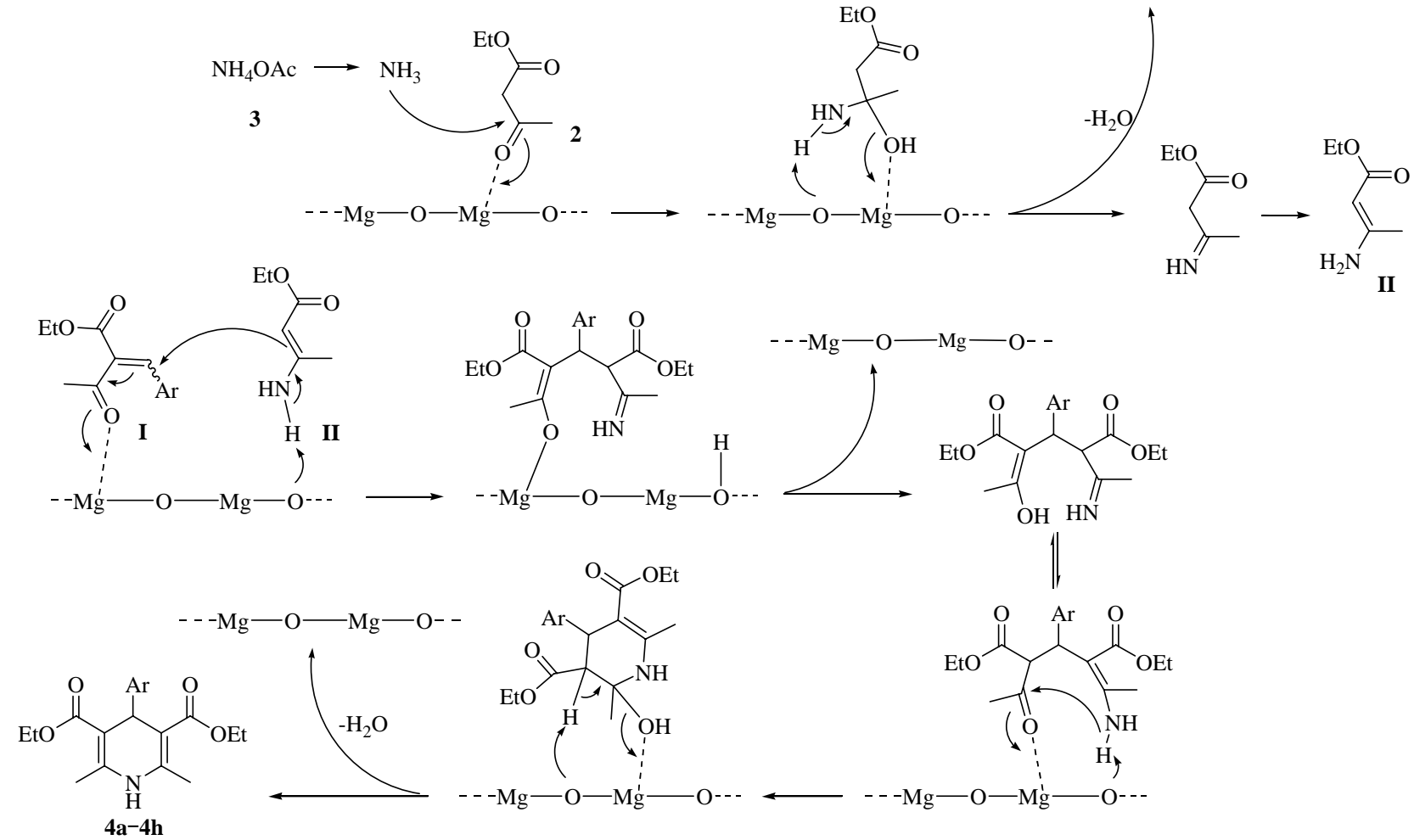

Scheme 2. Proposed mechanism for the formation of 1,4-dihydropyridines in the presence of MgO nanoparticles as catalyst.

\section{Conclusions}

MgO nanoparticles with high surface area were synthesized by a microwave-assisted sol-gel method using $\mathrm{Mg}\left(\mathrm{NO}_{3}\right)_{2} \cdot 6 \mathrm{H}_{2} \mathrm{O}$ and ammonia solution with deionized water as the solvent. The BET specific surface area was 243.2 $\mathrm{m}^{2} / \mathrm{g}$. XRD characterization showed pure cubic crystallites of MgO nanoparticles with the average particle size of 10.0 $\mathrm{nm}$. For comparison, MgO nanoparticles were also synthesized without irradiation by microwave. The broadening of the FWHM in the XRD peak indicated the formation of smaller particles when microwave irradiation was used. The
MgO nanoparticles showed high catalytic activity in the synthesis of Hantzsch 1,4-dihydropyridines from the reaction of aromatic aldehydes, ethyl acetoacetate, and ammonium acetate. Attractive features of this protocol are high yields, simple procedure with an easy work-up, and recyclability and reusability of the catalyst.

\section{Acknowledgements}

The authors would like to thank Dr F. F. Bamoharram for providing the nano $\mathrm{ZnO}$. The authors would also like to thank Dr Shahriar Khadem for editing the paper. 


\section{References}

1 Wagner G W, Bartram P W, Koper O, Klabunde K J. J Phys Chem B, 1999, 103: 3225

2 Davini P, Tartarelli R. Fuel, 1985, 64: 380

3 Duyar O, Durusoy H Z. Turk J Phys, 2004, 28: 139

4 Phillips J M. Appl Phys, 1996, 79: 1829

5 Hamet J F, Mercey B, Hervieu M, Raveau B. Physica C, 1992, 193: 465

6 Liu S W, Weaver J, Yuan Z, Donner W, Chen C L, Jiang J C, Meletis E I, Chang W, Kirchoefer S W, Horwitz J, Bhalla A. Appl Phys Lett, 2005, 87: 142905/1

7 Hattori H. Chem Rev, 1995, 95: 537

8 Mishakov I V, Bedilo A F, Richards R M, Chesnokov V V, Volodin A M, Zaikovskii V I, Buyanov R A, Klabunde K J. $J$ Catal, 2002, 206: 40

9 Chesnokov V V, Bedilo A F, Heroux D S, Mishakov I V, Klabunde K J. J Catal, 2003, 218: 438

10 Kumar D, Reddy V B, Mishra B G, Rana R K, Nadagoudac M N, Varmac R S. Tetrahedron, 2007, 63: 3093

11 Climent M J, Corma A, Iborra S, Mifsud M. J Catal, 2007, 247: 223

12 Zelmanov G, Semiat R. Water Res, 2008, 42: 492

13 Pucher P, Benmami M, Azouani R, Krammer G, Chhor K, Bocquet J F, Kanaev A V. Appl Catal A, 2007, 332: 297

14 Mirjafary Z, Saeidian H, Sadeghi A, Matloubi Moghaddam F. Catal Commun, 2008, 9: 299

15 Xue C H, Palaniappan K, Arumugam G, Hackney S A, Liu J, Liua H Y. Catal Lett, 2007, 116: 94

16 Jiu J T, Kurumada K I, Tanigaki M, Adachi M, Yoshikawa S. Mater Lett, 2004, 58: 44

17 Chadwick A V, Poplett I J F, Maitland D T S, Smith M E. Chem Mater, 1998, 10: 864

18 Bokhimi X, Morales A, Portilla M, Garcıa-Ruiz A. Nanostruct Mater, 1999, 12: 589

19 Subramania A, Kumar G V, Priya A R S, Vasudevan T. Nanotechnology, 2007, 18: 225601/1

20 Lopez T, Gomez R, Navarrete J, Lopez-Salinas E. J Sol-Gel Sci Technol, 1998, 13: 1043

21 Utamapanya S, Klabunde K J, Schlup J R. Chem Mater, 1991, 3: 175

22 Liang S H, Gay I D. Langmuir, 1985, 1: 593

23 Klabunde K J, Stark J, Koper O, Mohs C, Park D G, Decker S, Jiang Y, Lagadic I, Zhang D J. J Phys Chem, 1996, 100: 12142

24 Bokhimi X, Morales A, Lopez T, Gomez R. J Solid State Chem, 1995, 115: 411
25 Xu B Q, Wei J M, Wang H Y, Sun K Q, Zhu Q M. Catal Today, 2001, 68: 217

26 Matthews J S, Just O, Obi-Johnson B, Rees W S. Chem Vapor Depos, 2000, 6: 129

27 El-Shall M S, Slack W, Vann W, Kane D, Hanley D. J Phys Chem, 1994, 98: 3067

28 Ding Y, Zhang G T, Wu H, Hai B, Wang L B, Qian Y T. Chem Mater, 2001, 13: 435

29 Helble J J. J Aerosol Sci, 1998, 29: 721

30 Krishnakumar T, Jayaprakash R, Parthibavarman M, Phani A R, Singh V N, Mehta B R. Mater Lett, 2009, 63: 896

31 Davoodnia A, Rahimizadeh M, Atapour-Mashhad H, Tavakoli-Hoseini N. Heteroat Chem, 2009, 20: 346

32 Parida K M, Parija S. Sol Energy, 2006, 80: 1048

33 Moghaddam F M, Saeisian H. Mater Sci Engin B, 2007, 139: 265

34 Davoodnia A, Heravi M M, Rezaei-Daghigh L, TavakoliHoseini N. Chin J Chem, 2010, 28: 429

35 Davoodnia A, Khojastehnezhad A, Tavakoli-Hoseini N. Bull Korean Chem Soc, 2011, 32: 2243

36 Zeinali-Dastmalbaf M, Davoodnia A, Heravi M M, TavakoliHoseini N, Khojastehnezhad A, Zamani H A. Bull Korean Chem Soc, 2011, 32: 656

37 Khojastehnezhad A, Davoodnia A, Bakavoli M, TavakoliHoseini N, Zeinali-Dastmalbaf M. Chin J Chem, 2011, 29: 297

38 Davoodnia A, Tavakoli-Nishaburi A, Tavakoli-Hoseini N. Bull Korean Chem Soc, 2011, 32: 635

39 Jenkins R, Snyder R L. Chemical Analysis: Introduction to X-Ray Powder Diffractometry. New York: Wiley, 1996. 90

40 Klug H P, Alexander L E. X-Ray Diffraction Procedures. 2nd Ed. New York: Wiley, 1974. 656

41 Antonyraj C A, Kannan S. Appl Catal A, 2008, 338: 121

42 Debache A, Ghalem W, Boulcina R, Belfaitah A, Rhouati S, Carboni B. Tetrahedron Lett, 2009, 50: 5248

43 Heydari A, Khaksar S, Tajbakhsh M, Bijanzadeh H R. J Fluorine Chem, 2009, 130: 609

44 Murthy Y L N, Rajack A, Taraka Ramji M, Jeson Babu J, Praveen Ch, Aruna Lakshmi K. Bioorg Med Chem Lett, 2012, in press

45 Adharvana Chari M, Syamasundar K. Catal Commun, 2005, 6: 624

46 Sridhar R, Perumal P T. Tetrahedron, 2005, 61: 2465

47 Bamoharram F F. Synth React Inorg Met-Org Nano-Met Chem, 2011, 41: 571

48 Diez V K, Apesteguia C R, Di Cosimo J I. Catal Today, 2000, 63: 53 